\title{
The effect of Tinospora crispa extract against Spodoptera exigua on Spinacia oleracea
}

\author{
Norain Isa $^{1^{*}}$, Syazwani Aziz Satar ${ }^{2}$, Nor Aziyah Bakhari ${ }^{1}$, Siti Nur Amirah Diana Fadzilah, Lim Boon Tik ${ }^{1}$ and Wan Zarina Wan \\ Kamaruddin $^{1}$ \\ ${ }^{1}$ Chemistry Unit, Department of Applied Sciences, Universiti Teknologi MARA (UiTM) Cawangan Pulau Pinang, Pulau Pinang \\ ${ }^{2}$ Faculty of Chemical Engineering, Universiti Teknologi MARA (UiTM) Cawangan Pulau Pinang, Pulau Pinang
}

\begin{abstract}
The emergence of biodegradable pesticides as safe option has reduced the problems that result from the use of synthetic insecticides, thus creating a renewed interest in their development and use in integrated pest management of crops. The objective of this study was to investigate the insecticidal properties of the chloroform (CETC), ethanol (EETC), petroleum ether (PEETC) and ethyl acetate (EAETC) extracts of Tinospora crispa on small mottled millow moth (Spodoptera exigua) infesting spinach (Spinacia oleracea). The stem of the plants used in the experiment were collected from the locality, washed, shade dried, grind into powder and exhaustively extracted with four different solvents; starting with petroleum ether, followed by chloroform, ethanol, and ethyl acetate. A commercial pesticide, Cyperin (CCP) was included in the treatments as a standard check alongside the untreated (control). The experiment was laid out in a randomized complete block design (RCBD) with six treatments and four replicates. The efficacy of the treatments was based on reduction in Spodoptera exigua and percentage reduction in population of the pests. The results showed that EETC and PEETC significantly $(\mathrm{p}<0.05)$ reduced the population of Spodoptera exigua at $61.2 \%$ and $51.6 \%$ respectively. Though the other two; CETC and EAETC were not significant in reducing the population of the pests, they were better than the control. All the extracts of Tinospora crispa tested were not as effective as the commercial pesticide, Cyperin, CCP (91.5\%) in reducing Spodoptera exigua population. Among the tested extracts, EETC was found to be more effective, hence its use by resource poor farmers is recommended in the protection of Spinacia oleracea against the infestation of Spodoptera exigua.
\end{abstract}

| Tinospora crispa | Spodoptera exigua | Spinacia oleracea | Cyperin |

( 2013 Ibnu Sina Institute. All rights reserved. http://dx.doi.org/10.11113/mjfas.v9n2.93

\section{INTRODUCTION}

Tinospora crispa (Figure 1) is one of the natural herbs which is an indigenous climber plant that commonly grows wild in Asian countries including Malaysia known by various local name like 'akar patawali' and 'akar seruntum', an infusion of the stems is consumed as vermifuge and decoction of the whole plant is used to treat cholera and diabetes among the Malay community. Its stem has been used by traditional folklore for various therapeutic purposes such as treatment for diabetes, hypertension, stimulation of appetite and protection from mosquito bites [1].

Sometimes it was also used as an anti-parasitic agent in both man and domestic animals [1]. This plant has many traditional uses for the treatment of the skin and would make an excellent addition to skin care product for the mature woman between 40 and 60 who wants to maintain her beauty and the whole plant contains a bitter principle, columbine, $2.22 \%$, traces of alkaloid, and a glucoside. It also contains an amorphous bitter principle, picroretine, and traces of berberine.
The bitter components of picroretine can kill pests [2].

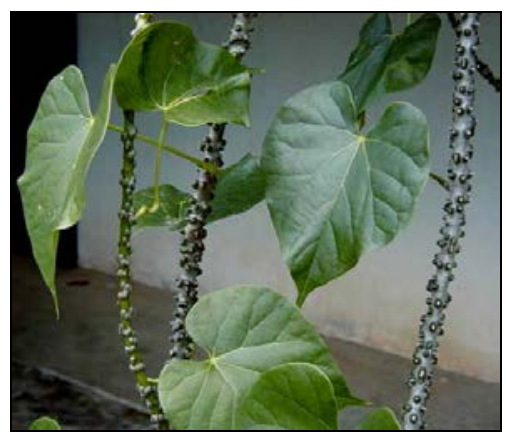

Fig. 1. Tinospora crispa

Spinach or Spinacia oleracea (Figure 2) is now widely grown in the temperate regions of the world. The plant requires a constant and uniform supply of water in order to obtain a good crop of high quality. In Malaysia, spinach was planted for domestic purpose and to be exported to Singapore and Brunei. Spinach is a herb in 
medium size where it can achieve height of $45 \mathrm{~cm}$ to $1 \mathrm{~m}$. It has non-woody stem and the leaves are alternate, simple, ovate to triangular-based, very variable in size from about 2-30 cm long [3].

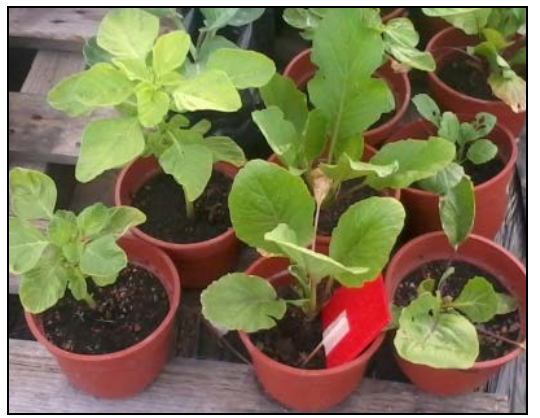

Fig. 2. Spinach or Spinacia oleracea

The Beet Armyworm (Figure 3) or Small Mottled Willow moth (Spodoptera exigua) is one of the bestknown agricultural pest insects. It is also known as the asparagus fern caterpillar, and the adult moth is known in the UK (where it is an introduced species and not known to breed) as the small mottled willow. It is native to Asia, but has been introduced worldwide and is now found almost anywhere its many host crops are grown. They are greenish-brown cutworms, soft and bulging caterpillars with dark longitudinal stripes [4].

The adult is a drab brown or grey moth 2 to $3 \mathrm{~cm}$ in wingspan. The larvae feed on the foliage of plants, and can completely defoliate small ones. Smaller larvae devour the parenchyma of leaves, so that all that remains is the thin epidermis and veins. Larger larvae tend to burrow holes through thick areas of plants. For example, they will burrow straight into a head of spinach rather than neatly removing tissue from one particular leaf. This renders the produce unmarketable. They attack buds and new growth on plants, preventing flowers from opening, new leaves from sprouting, and vegetables from developing. As the smaller larvae move about they leave strands of silk behind, netting the leaves with a silvery film $[4,5]$.

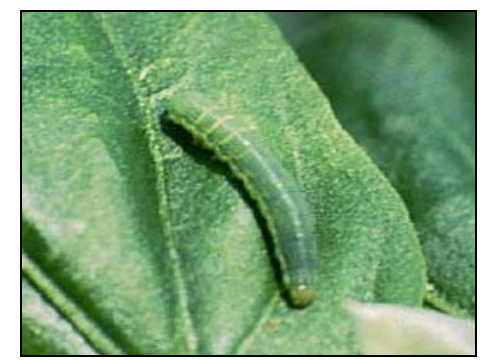

Fig. 3. The Beet Armyworm or Small Mottled Willow Moth (Spodoptera exigua)

The widehost range of the beet armyworm includes asparagus, beans and peas, sugar and table beets, celery, cole crops, lettuce, potato, tomato, cotton, cereals, oilseeds, tobacco, many flowers and a multitude of weed species. The beet armyworm does not tolerate cold. It can overwinter in warm areas, such as in Florida and Hawaii, but in colder areas it dies off during the winter and the region is reinvaded by the adult moth as the weather warms and crop plants sprout $[4,5]$.

Most of the farmers are not aware with the ill effect of chemical pesticide and still using most of the systemic and organic pesticides to control pest [6]. Injudicious and continuous use of pesticides may be deleterious to agroecosystem, public health and create residual problems [7-9]. Therefore, in recent years many scientists have switched to use of botanicals as well as plant extracts instead of chemical pesticides for the control of pest of agricultural importance. The botanicals are more compatible with the environmental components, eco-friendly with plant health and non-hazardous to human beings. Therefore, in present investigations the bio-efficacy of four extracts of Tinospora crispa stem were tested against Spodoptera exigua on Spinacia oleracea.

\section{EXPERIMENTAL}

\subsection{Materials and method}

The stem of Tinospora crispa were collected from locality, Parit Buntar, Perak, Malaysia and identified by comparison with example of existing specimens in the herbanium, School of Pharmaceutical Science, USM (serial number 011). Fresh plant sample (25 kg) were cleaned and cut into small pieces $( \pm 1 \mathrm{~cm})$ and dried in the laboratory of Chemistry, UiTM Cawangan Pulau Pinang under shaded area.

Thereafter, to make the fine powder of those, the dried of stem were grind into powder $(4.0 \mathrm{~kg})$ for next process. Further, four different solvent; ethanol, petroleum ether, ethyl acetate, and chloroform respectively were used for extraction process to produced of four types of pesticide; ethanol extract (EETC), petroleum ether extract (PEETC), ethyl acetate (EAETC) and chloroform extract (CETC) of Tinospora crispa. Extraction was done by using Soxhlet apparatus about 6 to 8 hours for approximately for $\pm 0.1 \mathrm{~kg}$ powder of Tinospora crispa at 60 to $70^{\circ} \mathrm{C}$. The product then will be filtered and the remainder powder will be refluxed.

Side by side,Spinacia oleracea plants were grown in micro plot sized $3 \times 4$ meter (each four replicated) in the experimental field (behind Pusat Islam UiTM Cawangan Pulau Pinang) from April to October 2012. The experiments were laid out in randomized complete block design (RCBD) with six treatments and four replicates.

To test the bio-efficacy of stem extract of Tinospora crispa against Spodoptera exigua on Spinacia oleracea, four types of bio-pesticide produced from stem extracts of Tinospora crispa; EETC, PEETC, EAETC and CETC were applied with the help of simple hand spray $(500 \mathrm{~mL})$, on randomly selected Spinacia oleracea plants of one month 
age in the experimental field. Five sprays of each different bio-pesticide (EETC, PEETC, EATC and CETC) were applied at one-week interval after the appearance of Spodoptera exigua. The percent reduction of spodoptera exigua population was recorded after $24 \mathrm{~h}$ of the spray. To compare the effectiveness of extracts of Tinospora crispa, a Control (distilled water mixed with Tween 20) and Cyperin as commercial pesticide (CCP) were also run simultaneously. The data obtained was subjected to oneway ANOVA while differences in treatment means were separated by Student Newman Keuls (SNK) test at 5\% level of significance. All statistical analyses were done by SPSS version 17.0 for windows.

\section{RESULTS \& DISCUSSION}

The results of the effect of bio-pesticide produced from solvent extracts of Tinospora crispa and commercial pesticide, Cyperin (CCP) to control small mottled millow moth infesting spinach were presented in Table 1 which evaluated from the reduction of numbers of small mottled millow moth after application of treatments. In the first spray after application of treatments, EETC show the highest \% reduction against Spodoptera exigua, followed by CCP, PEETC, EAETC, CETC and Control. For second, third, fourth and fifth spray, CCP show the highest \% reduction which followed by EETC, PEETC, EAETC, CETC and Control as shown in Figure 4. Among different types of bio-pesticide (EETC, EAETC, PEETC, CETC) and CCP for treatments to reduced pest, CCP as commercial pesticide significantly $(\mathrm{p}<0.05)$ reduced maximum Spodoptera exigua population followed by EETC and PEETC during first (41.29, 43.71 and $37.76 \%)$, second (73.02, 53.14 and 36.24\%), third (76.91, 53.18 and 37.03\%), fourth (76.66, 56.55 and 44.51\%) and fifth (91.52, 61.37 and 51.63) sprays respectively.

From the results, EATC and CETC were not significantly reduced the population of small mottled millow moth, which their \% reduction were low and not effective to control of Spodoptera exigua, but they were better than negative control treatment (untreated). Although, the Tinospora crispa extracts were not as effective as the commercial pesticide, CCP, but EETC and PEETC were effective which found significantly $(\mathrm{p}<0.05)$ reduced Spodoptera exigua. The Student Newman Keuls (SNK) comparisons indicated that the significant difference was between the following pairs: CCP and EETC, CCP and PEETC, CCP and EAETC, CCP and CETC, CCP and C, EETC and EAETC, EETC, EETC and CETC, EETC and C, PEETC and EAETC, PEETC and CETC, and PEETC and $\mathrm{C}$ as shown in Table 2.

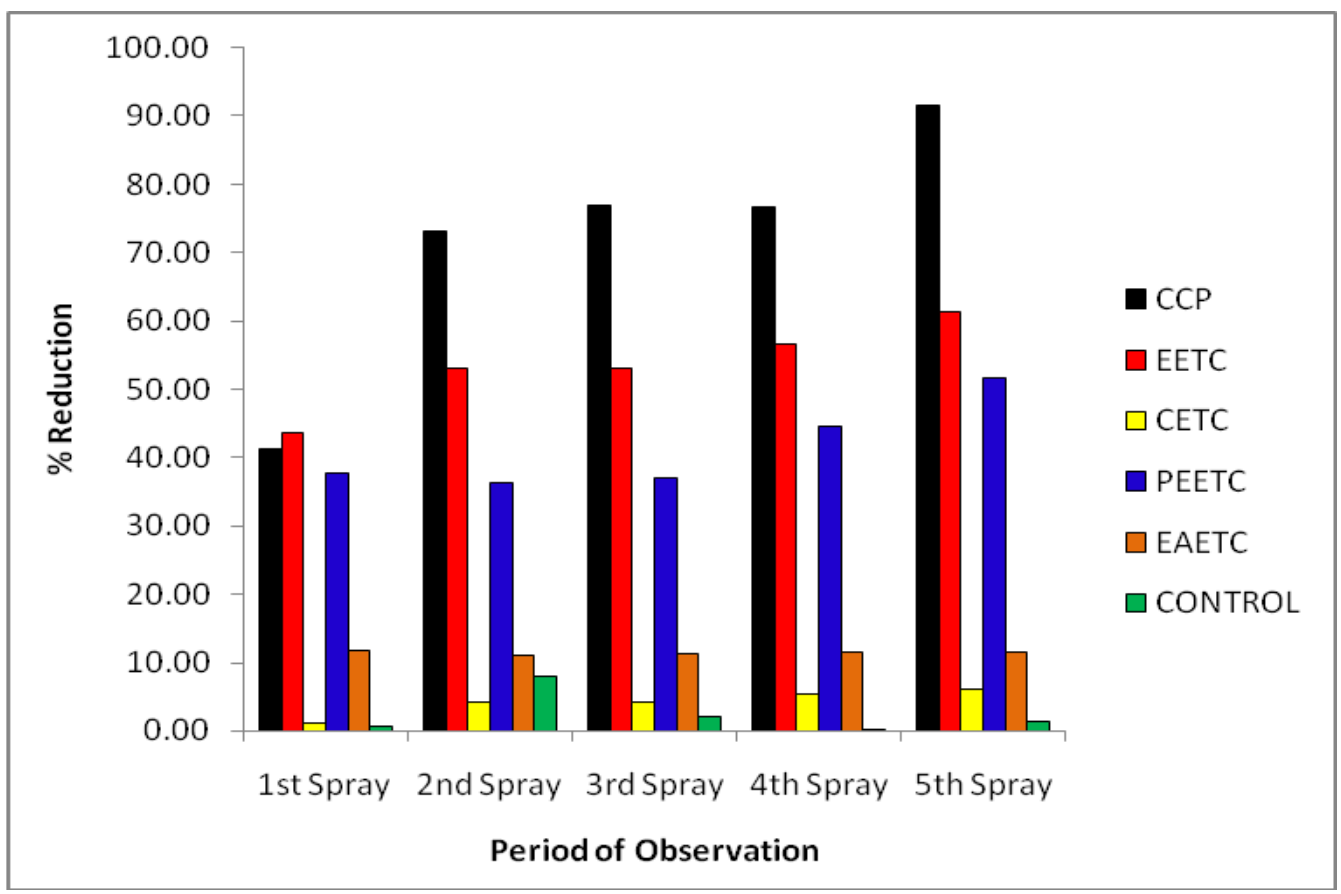

Fig. 4. Percentage reduction of Spodoptera exigua after each spray of treatments. 
Table 1. Bio-efficacy of EETC, PEETC, EAETC, CETC, CCP and C against Spodoptera exigua infesting Spinach plant.

\begin{tabular}{|c|c|c|c|c|c|c|c|c|c|c|c|c|c|c|c|c|}
\hline & \multirow[b]{2}{*}{ 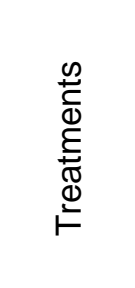 } & \multirow{2}{*}{ 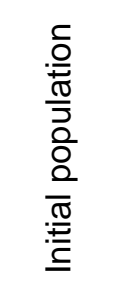 } & \multicolumn{2}{|c|}{$1^{\text {st }}$ spray } & \multirow{2}{*}{ 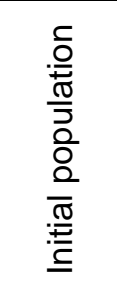 } & \multicolumn{2}{|c|}{$2^{\text {nd }}$ spray } & \multirow{2}{*}{ 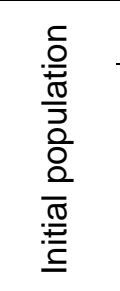 } & \multicolumn{2}{|c|}{$3^{\text {rd }}$ spray } & \multirow{2}{*}{ 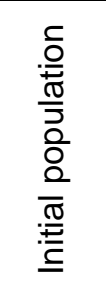 } & \multicolumn{2}{|c|}{$4^{\text {th }}$ spray } & \multirow{2}{*}{ 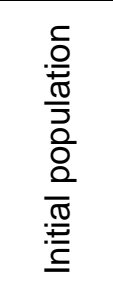 } & \multicolumn{2}{|c|}{$5^{\text {th }}$ spray } \\
\hline & & & 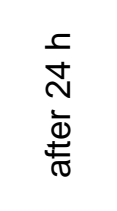 & $\begin{array}{l}\frac{\sigma}{0} \\
\frac{0}{\mathrm{U}} \\
\frac{\mathrm{D}}{\mathrm{d}} \\
\frac{0}{0}\end{array}$ & & 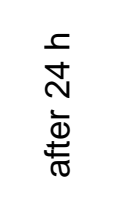 & $\begin{array}{l}\frac{.}{0} \\
\frac{0}{0} \\
\frac{D}{0} \\
\frac{0}{0} \\
0\end{array}$ & & 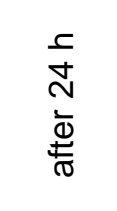 & $\begin{array}{l}\frac{.}{0} \\
\frac{0}{0} \\
\frac{0}{0} \\
\frac{0}{0}\end{array}$ & & $\begin{array}{l}\frac{c}{ \pm} \\
\stackrel{ \pm}{N} \\
\stackrel{\bar{\varpi}}{\frac{ \pm}{\sigma}}\end{array}$ & $\begin{array}{l}\frac{.}{0} \\
\frac{0}{0} \\
\frac{D}{0} \\
\frac{0}{0} \\
0\end{array}$ & & 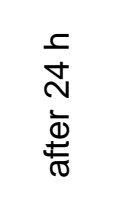 & $\begin{array}{l}\frac{c}{0} \\
\frac{0}{0} \\
\frac{D}{0} \\
\frac{0}{0} \\
0\end{array}$ \\
\hline+ & $\mathrm{CCP}$ & 5.11 & 3.00 & 41.29 & 5.56 & 1.50 & 73.02 & 7.58 & 1.75 & 76.91 & 8.57 & 2.00 & 76.66 & 26.52 & 2.25 & 91.52 \\
\hline 2 & EETC & 23.54 & 13.25 & 43.71 & 35.21 & 16.5 & 53.14 & 18.69 & 8.75 & 53.18 & 25.89 & 11.25 & 56.55 & 18.74 & 7.24 & 61.37 \\
\hline 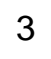 & CETC & 43.98 & 43.5 & 1.09 & 20.89 & 20.00 & 4.26 & 27.41 & 26.25 & 4.23 & 23.52 & 22.25 & 5.40 & 23.69 & 22.25 & 6.08 \\
\hline 4 & PEETC & 7.23 & 4.50 & 37.76 & 7.45 & 4.75 & 36.24 & 45.26 & 28.50 & 37.03 & 8.56 & 4.75 & 44.51 & 53.24 & 25.75 & 51.63 \\
\hline 5 & EAETC & 15.30 & 13.50 & 11.76 & 33.2 & 29.50 & 11.14 & 42.89 & 38.00 & 11.40 & 29.10 & 25.75 & 11.51 & 22.05 & 19.5 & 11.56 \\
\hline 6 & Control & 30.41 & 30.25 & 0.53 & 29.57 & 27.25 & 7.85 & 27.58 & 27.00 & 2.10 & 28.80 & 28.75 & 0.17 & 28.91 & 28.5 & 1.42 \\
\hline
\end{tabular}

Table 2. Student Newman Keuls (SNK) comparison analysis between different treatments ( ${ }^{a}$ significant different : $\left.p<0.05\right)$

\begin{tabular}{cccccccc}
\hline \multirow{2}{*}{ Types of extraction } & & CCP & EETC & PEETC & EAETC & CETC & Control \\
& MEAN & 2.1 & 11.35 & 13.65 & 25.5 & 26.85 & 28.6 \\
\hline CCP & 2.1 & 0 & & & & & \\
EETC & 11.35 & $9.25^{\mathrm{a}}$ & 0 & & & & \\
PEETC & 13.65 & $11.55^{\mathrm{a}}$ & 2.3 & 0 & & & \\
EAETC & 25.5 & $23.4^{\mathrm{a}}$ & $14.15^{\mathrm{a}}$ & $11.85^{\mathrm{a}}$ & 0 & & \\
CETC & 26.85 & $24.75^{\mathrm{a}}$ & $15.5^{\mathrm{a}}$ & $13.2^{\mathrm{a}}$ & 1.35 & 0 & \\
Control & 28.6 & $26.5^{\mathrm{a}}$ & $17.25^{\mathrm{a}}$ & $14.95^{\mathrm{a}}$ & 3.1 & 1.75 & 0 \\
\hline
\end{tabular}


Previous studies by different researchers revealed that Tinospora. crispa is one of the most promising biopesticides, which is effective against green leafhopper and brown planthoppers [9]. The water extracts of Tinospora crispa showed systemic and ovicidal toxicities and growth inhibitory effect [10]. Study on the effect of Tinospora crispa leaf extract showed that the extract could reduced feeding activity of $P$. xylostella larvae in cabbage under both laboratory and field conditions. Application of the leaf extract at 0.1 to $4.0 \%$ could reduce feeding activity by 19.5 to $100 \%$. Application of the leaf extract in the field at 0.1 to $1.0 \%$ reduced significantly larval density, damage intensity while increasing the percentage of plants that produced heads and the weight of individual heads. Applications at $0.5,0.7$ and $1.0 \%$ were comparable to the application of $0.075 \%$ profenofos [11].

\section{CONCLUSION}

The overall results of this study showed that EETC and PEETC obtained from extracts of Tinospora crispa were effective and significantly $(\mathrm{p}<0.05)$ in reducing the population of Spodoptera exigua on Spinach plant. Although, the \% reduction of EETC and PEETC not as good as CCP, commercial pesticide, but these biopesticides can be used as potential source of sustainable eco-friendly botanical pesticide to protect from pest Spodoptera exigua. Among the tested extracts, EETC was found to be more effective; hence, its use by resource poor farmers is recommended in the protection of Spinacia oleracea against the infestation of Spodoptera exigua.

\section{ACKNOWLEDGEMENT}

The authors thank the Department of Applied Sciences and Faculty of Chemical Engineering, Universiti Teknologi MARA (UiTM) Cawangan Pulau Pinang, Malaysia for all the facilities as well as to Malaysian Government, FRGS Grant code: 600-RMI/ST/FRGS 5/3/Fst (232/2010) for funding the project.

\section{REFERENCES}

[1] I.A. S. M. Shahriar Mohammad and M. Haque Aminul. Journal of Pharmacetical and Biomedical Sciences, 13 (2011) 13.

[2] C. Anthony and J.P.C. Dweck. A Review Paper of Tinospora crispa (2003).

[3] P. Santamaria J. Sci. Food Agric., 86 (2006), 10-17.

[4] N.C.D . Prabhaker., A.N. Kishaba and D.E. Meyerdirk. Journal of Economic Entomology 79 (1986) 39-41.

[5] J.L. Capinera. Handbook of vegetable pests. Academic Press. (2001) 729.

[6] O. Onunkun. JBiopest, 5 (supplementary) (2012) 62-67

[7] K.R.N. Reddy, S.B. Nurdijati and B. Salleh. African Journal of Microbiology Research 4(23). (2010) 2562-2565.

[8] D. Adjaye-Gbewonyo, E.C. Quaye and D.A. Wubah. Journal of Young Investigators 20, (2010)

[9] R.P. Leonardo B.S. Thesis, UPLB, College, Laguna (1983).

[10] B. Morallo-Rejesus, and A. S. Sayaboc. Guide to control diamondback moth. Los Banos, Laguna: PCARRD, 1992. 16

[11] S. Dewa Ngurah, I. S Wayan, A. Nyoman and O. Kanju. J. ISSAAS., 9 (2), (2003) 18-24. 